\title{
Assessment of above ground biomass of Trees outside Forest (TOF) in the Context of Climate Change
}

\author{
Him Lal Shrestha ${ }^{1 *}$, Anu Rai ${ }^{2}$ and Puspa Dhakal ${ }^{3}$ \\ ${ }^{1}$ Kathmandu Forestry College, Nepal \\ ${ }^{2}$ eG-Tech Pvt. Ltd., Lalitpur, Nepal \\ ${ }^{3}$ RECOFTC, Kathmandu, Nepal
}

*Corresponding author: Him Lal Shrestha, Kathmandu Forestry College, Nepal, Tel: +977-1-5147211; Email: hlshrestha@gmail.com

\section{Research Article}

Volume 4 Issue 1

Received Date: December 27, 2019

Published Date: February 07, 2020

DOI: $10.23880 /$ jenr-16000186

\section{Abstract}

The Tree Outside Forest (TOF) play important ecological, social and economic role. In Nepal, TOF are mostly used by smallholder farmers to manage their needs from the farm trees mainly for the livestock keeping and agriculture. These trees also play crucial role on combating climate change impacts. But despite its importance, the TOF have largely been ignored in the forest statistics in Nepal. To overcome this problem an assessment of the trees outside forest has been conducted in Bhimsen Rural Municipality - 6 using satellite imageries and field based measurements. Using data acquired from World View Panchromatic, tree delineation was conducted with ITC technique. 9 compartment of $5 \mathrm{~km} * 5 \mathrm{~km}$ grid with the division of $500 * 500 \mathrm{~m}$ was assigned. The tree roundness, crown area, and length/width ratio of the trees were calculated from the satellite image. Likewise, field based measurements were conducted to quantify the tree based biomass and carbon stock and the household survey was done to estimate the annual harvest from those trees. In the nine compartments made for image analysis, the Trees Outside Forest count was found to be a total of 31520 with an average of 2700 trees per hectare. A total of 118.4 tons/ha of biomass and 55.6 tons/ha carbon is stored on TOF in the study area. Hence, we recommend that the contribution from the Trees outside Forest be accounted into the national carbon statistics.

Keywords: Tree Outside Forest; Farm trees; GIS; Satellite Imageries; Image Segmentation; Carbon Sequestration; Biomass

Abbreviations: TOF: Trees Outside Forest; UNFCCC: United Nations Framework Convention on Climate Change; FYM: Farm-Yard-manure; NFMA: National Forest Monitoring and Assessment; LULC: Land Use Land Cover; AGB: Above Ground Biomass.

\section{Introduction}

Trees outside forest (TOF) are defined as the trees, which have attained $10 \mathrm{~cm}$ or more diameters at breast height, available on land, which are not notified as forests [1]. The TOF play important ecological, social and economic role as it provides basic ecosystem services and goods to the people
[2-4]. They are basically known as woodlands, shrubberies, urban trees, scattered trees, farm trees and many more. People have managed TOF in the form of agroforestry and urban plantings for longer term $[5,6]$ for instance in the form of agroforestry systems [7]. However, TOF have mostly been left out in most forest statistics, assessments and policies because they are typically split among the various categories of agroforestry, urban and rural forestry [8]. But the interest in TOF and its assessments have emerged basically because the protection and enhancement of tree cover in non-forest land will be needed to complement the protection of forest areas [9]. Trees are typically the largest components of aboveground biomass in terrestrial ecosystem $[10,11]$ and 


\section{Journal of Ecology and Natural Resources}

regardless of their location they are important for carbon storage. Likewise, reporting obligations from international conventions has also made it necessary for conduct TOF assessment particularly the United Nations Framework Convention on Climate Change (UNFCCC) and United Nations Convention on Biological Diversity (UN-CBD) have urged on keeping up-to- date information on tree resources within and outside forests [12]. Likewise, the Kyoto protocol has particularly, emphasized on the inclusion of TOF in national forest monitoring systems [13]. The assessments have given some truly insightful information such as $73 \%$ of the national above-ground tree biomass is accumulated outside forest in Bangladesh [14]. Unfortunately, such national assessment is not available in case of Nepal.

Farm trees provides fodder, food, farm-yard-manure (FYM) and fuelwood (4Fs), high value crops - coffee, teas, edibles, medicinal plants. food and income from cultivated, agroforestry, and naturally growing trees in farm land and urban land constitute an important component on individual household food supply [15]. These trees support the daily livelihood of people in both direct and indirect way. The cultural benefits of TOF extend to neighborhoods and environmental benefits may accrue to whole urban area, like the reduction of urban heat island effect [16]. TOF provide various ecosystem services such as control over soil erosion, nutrient and water cycling, biodiversity conservation or pest control [17-19]. The $80 \%$ of the requirements of the wood-based industries are met from TOFs [20]. TOF also play an important role in both the sequestration and storage of carbon [21] considering as mitigation alternatives. In the context of Climate Change, the assessment of TOF has become much more relevant as TOF make an important contribution to climate change mitigation but are not systematically accounted for in either global carbon budgets or national carbon accounting. Globally, it has been estimated that about 33 giga tones of biomass carbon is stored in trees on agricultural land using coarse spatial resolution satellite data [2]. On a finer scale, the data of TOF is rare and availability varies typically across fragmented institutions and stakeholder [14]. But there are exceptions where systematic study has been conducted such as the National Forest Monitoring and Assessment (NFMA) programme by FAO [14] and some of the country's own assessment such as China's national forest inventory [22].

In Nepal plantation of trees outside forest has been playing positive roles in carbon enhancement and biodiversity conservation [17]. Smallholder farmers in Nepal are managing their needs from the farm trees mainly for the livestock keeping and agriculture. In rural farms of Nepal, most of the farmers depend on the perennial trees other than annual crops for fuelwood, fodder, and supplementing materials for the agriculture. Some of the requirements needs fulfilled from the forest trees whereas the farm trees basically fulfil the requirement of the farmers of food, fodder, fuelwood, agricultural implements. Farm trees with the focus on high value crops provide the income generating services as a livelihood support. Those trees also play crucial role on combating climate change impacts providing ecosystem services other than the direct services. In this context the study has been envisioned. The main purpose of the study was the assessment of number trees outside the forest area, quantifying the above ground biomass using remote sensing data, linking TOF to the ecosystem services and climate changes issues. Thus, TOF is becoming as the part of agroecosystem contributes on symbiotic relations with cultivating crops and fauna. The paper attempted to assess the density of farm trees and its biomass estimates to quantify carbon sequestration in the domain of trees other than forest areas.

\section{Materials and Methods}

\section{Data and Materials}

The data used for the study was from various sources namely remote sensing data of WorldView PAN, Land use land cover (LULC) data derived using Landsat imageries, social and demographic data and field measurement data were used to supplement the assessment (Table 1)

\begin{tabular}{|c|c|c|c|}
\hline S.No & Data & Source & Characteristics \\
\hline 1 & LULC & ICIMOD & $30 \mathrm{~m}$ \\
\hline 2 & Satellite imageries & WorldView & $50 \mathrm{~cm}$, PAN \\
\hline 3 & Population data & CBS, GON & Ward level population \\
\hline 4 & Tree parameters & Field measurement & \\
\hline
\end{tabular}

Table 1: Data used and their characteristics.

\section{Study Area}

The study was conducted in Bhimsen Gaunpalika - 6 of Gorkha District, Gandaki Province, Nepal (Figure 1). The area of the ward is 18.9 sq. $\mathrm{km}$. There are 831 household in this ward with a total population of 3,406 consisting of about $42 \%$ male and $58 \%$ female [23]. The study area comprises of $55 \%$ forest area and $45 \%$ of settlement, agriculture, barren 
land [24]. Ashrang VDC lies between $27^{\circ} 58.29^{\prime} \mathrm{N}-28^{\circ}$

altitudinal variation is from $500 \mathrm{~m}$ to $1200 \mathrm{~m}$. $1.50^{\prime} \mathrm{N}$ Latitude and $84^{\circ} 40.63^{\prime} \mathrm{E}-84^{\circ} 45.16^{\prime} \mathrm{E}$ Longitude and

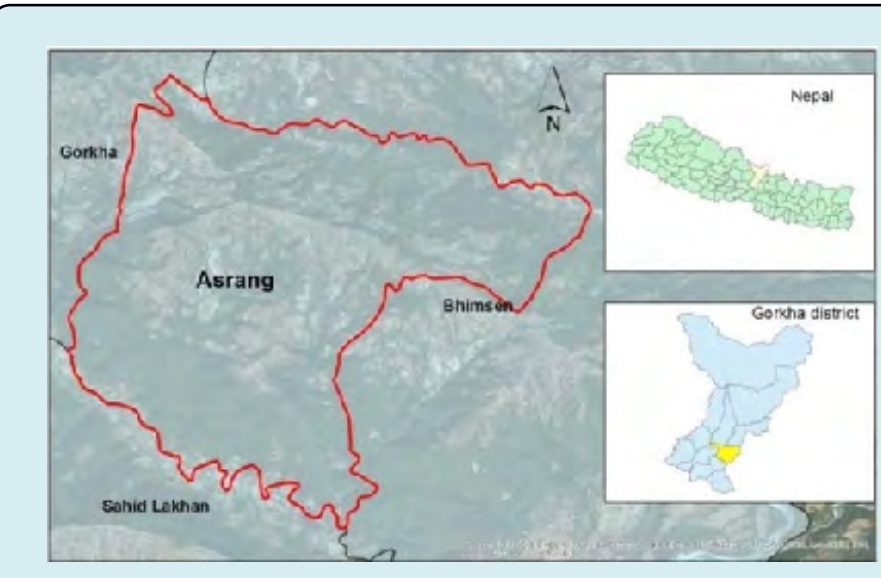

Figure 1: Location of study area.

\section{Data Collection and sampling}

The study has utilized both remote sensing data and field measurement data to infer the results. The assessment of
TOF was carried out using typical assessment technique rather than conventional forest inventory because of specific characteristics of the trees such as density, diameter distribution on the forest and non-forest land classes [12].

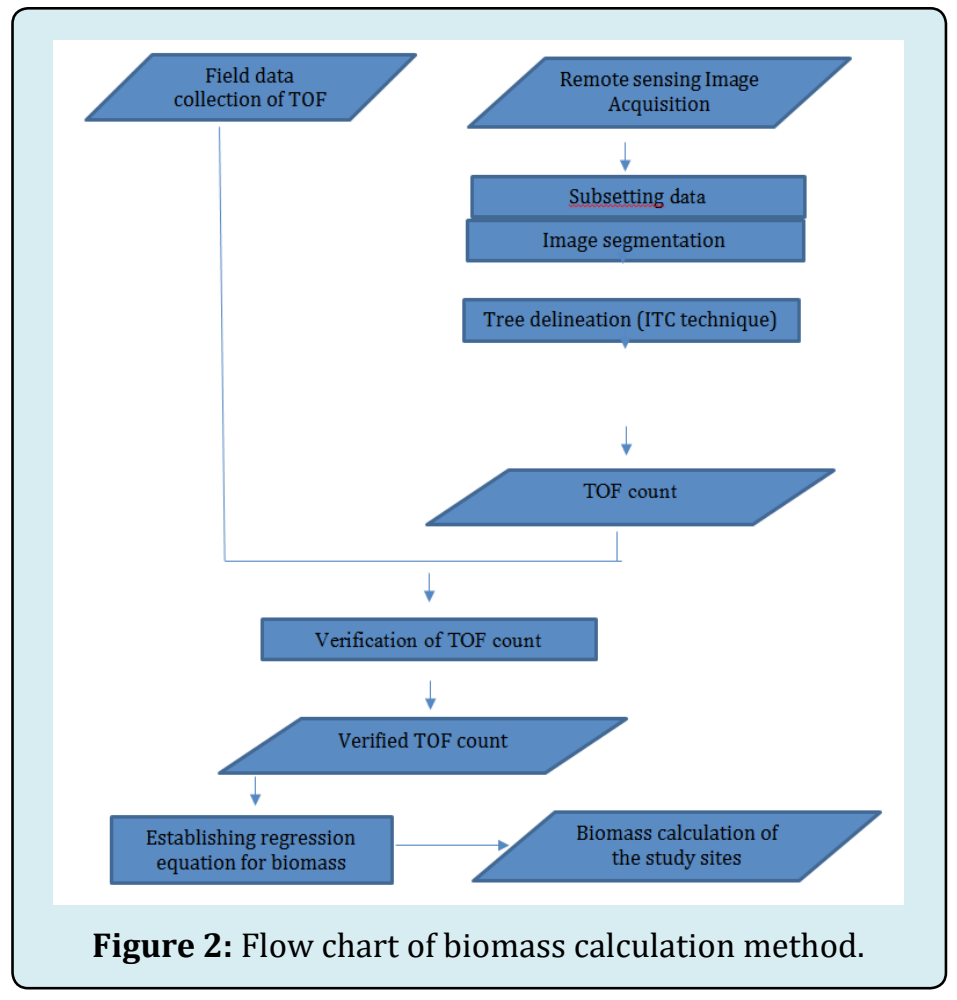

Using remote sensing data is challenging for TOF assessment as detection of TOF could be difficult because of their small extent and sparse distribution [12]. Hence, a high resolution image in preferred however, this presents a problem particularly the 'H-resolution problem' as a higher spatial resolution leads to increased spectral variation of landscape features making it difficult to statistically separate classes using traditional pixel-based classification methods resulting in reduced classification accuracy [25]. On the other hand, field measurement can only be available to a 
certain extent [12]. Hence, a blend of remote sensing imagery use with integration of field measurement is preferred for
TOF assessment [12]. This method is also employed in our assessment (Figures 2 and 3).

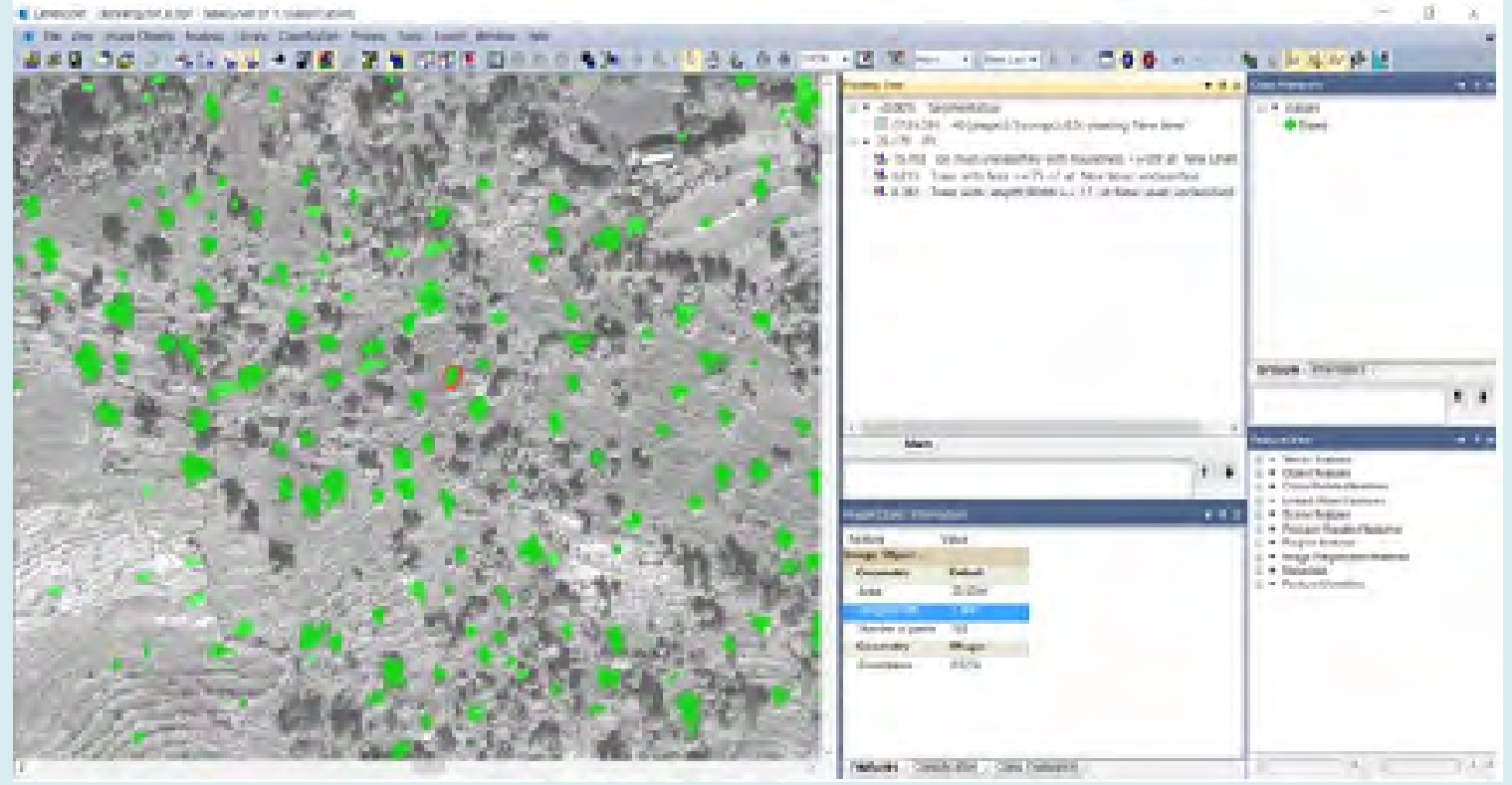

$3 \mathrm{~A}$

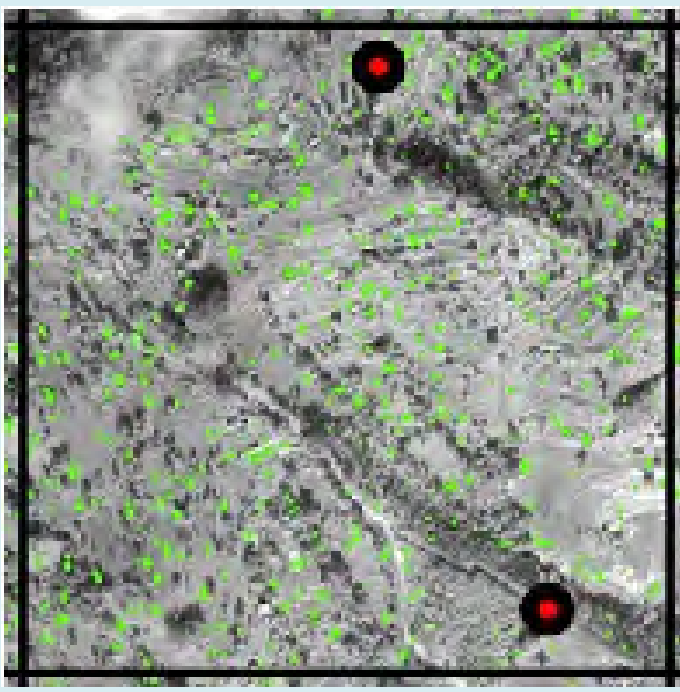

3B

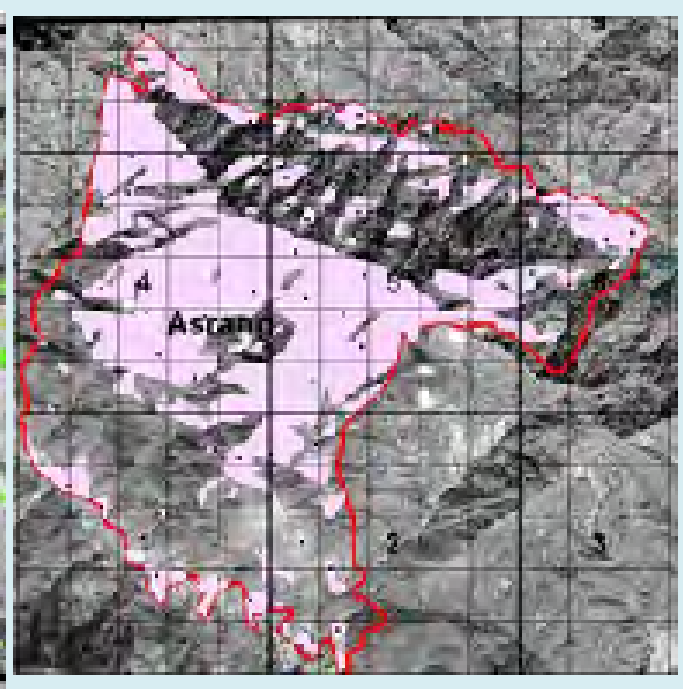

$3 \mathrm{C}$

\section{- $-<0.001 \mathrm{~s}$ Segmentation \\ $=27: 33.59340$ [shape:0.1 compct.0.5] creating 'New Level' \\ - 25.672 ITC \\ 1. 15.703 on main unclassified with Roundness $<=0.9$ at New Level: \\ 4. 0.015 Trees with Area $>=75 \mathrm{~m}^{2}$ at New Level: unclassified \\ 4. 0.282 Trees with Length $\backslash$ Width $>=2.3$ at New Level: unclassified}

D

Figure 3: Process of Remote Sensing data analysis. (A. Image segmentation, B. Sample plot allocation map for tree delineation, C. Compartment division map for tree delineation and D. Rules for tree delineation). 


\section{Remote Sensing Data and Processing}

Remote sensing data acquisition was carried out with WorldView Panchromatic satellite data. Image subset operation was done to retrieve the area of interest for the study areas. The LULC data derived from Landsatimages were used [24] for the stratification of the study area which falls under the cultivation. Then image segmentation was done using selected algorithms among the different segmentation approaches available. This was followed by Tree delineation with ITC technique where $2.5 \mathrm{~km} * 2.5 \mathrm{~km}$ grid was formed in the satellite image and random plots were allocated to overcome the 'H-resolution problem'. 9 compartment of $5 \mathrm{~km} * 5 \mathrm{~km}$ grid with the division of $500 * 500 \mathrm{~m}$ was assigned. Roundness, crown area, and length/width ratio of the trees were calculated from the satellite imageries and used for the OBIA to generate CPA.

\section{Field Measurement and Biomass Quantification}

Field measurement was done with 63 samples random points were taken with $1 \%$ sampling intensity with the plot size of $500 \mathrm{~m}^{2}$. Height and DBH of the trees were measured. The biomass of individual trees was estimated using allometric equation suggested by Chave JC, et al. [20] for individual trees and later calculated for the plots and compartments assessing biomass per hectare. The equation suggested by Chave JC, et al. [20] for the moist region is used for the calculation of above ground biomass for each tree. The plot total further analyzed to get plot total and per hectare biomass in each plot. The plot average per hectare biomass further analyzed to get the average per hectare biomass in each compartments. The equation is as follows:

$$
\mathrm{AGB}=0.0509 * \rho * \mathrm{DBH}^{2} * \mathrm{Ht}
$$

Where,

AGB $=$ Above Ground Biomass

$\rho=$ specific wood density of tree species

DBH $=$ Diameter at Breast Height

$\mathrm{Ht}=$ Height of the tree

The allometric equation for the estimation of above ground biomass (AGB) of trees for the moist forest suggested by Chave JC, et al. [20] was used. The specific wood density for the fodder trees were taken from the Master Plan for Forestry Sector in Nepal and FAO.

\section{Establishing Regression Equation and Prediction}

The biomass data calculated for the individual trees and the crown percentage areas calculated using ITC technique were further processed for the establishment of the regression relation to get the allometric equation between the CPA and field measured biomass of individual trees. The allometric equation best fit between CPA and biomass is used to predict the biomass of all individual trees in the study area (Figure 4).

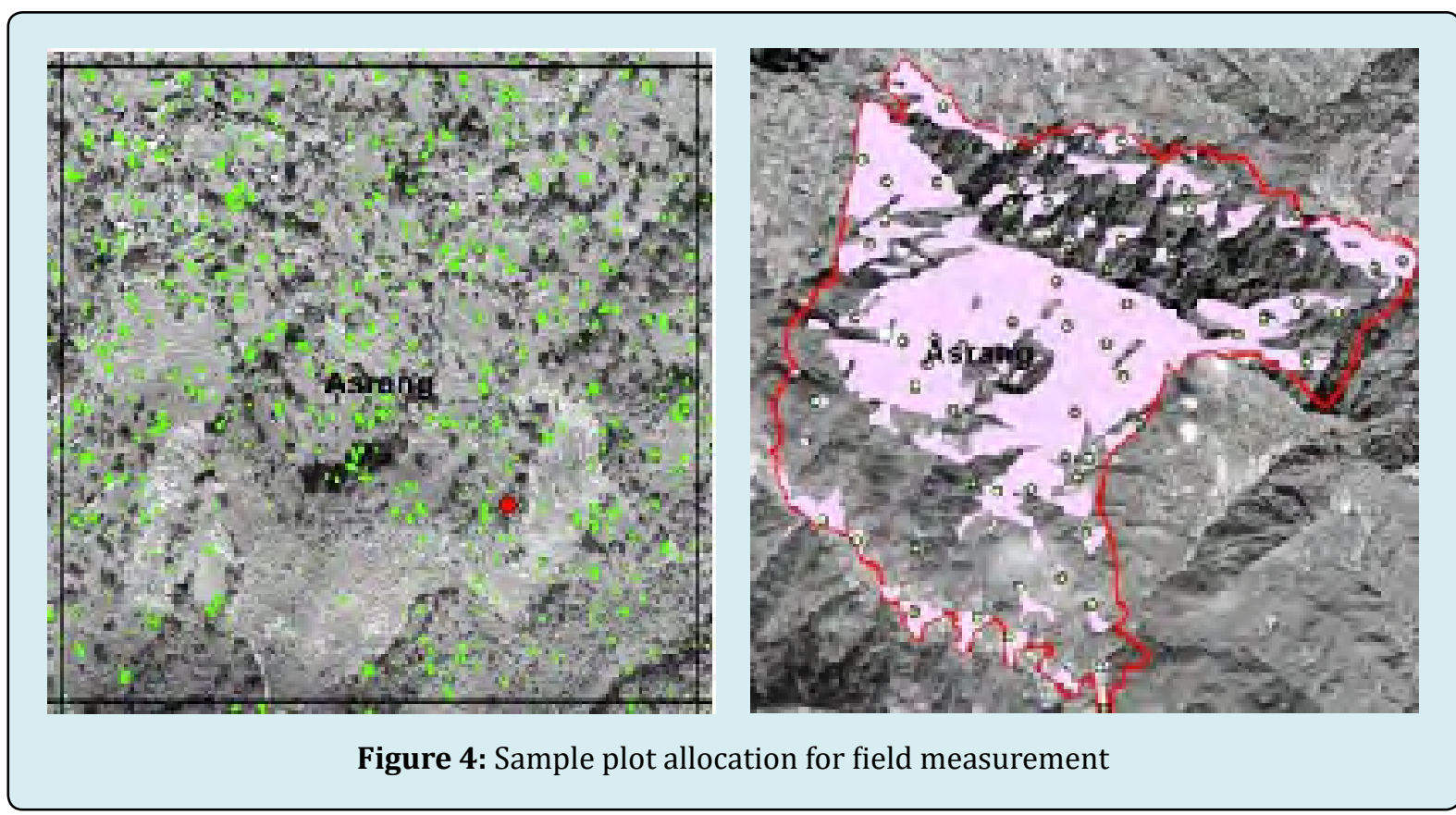




\section{Results and Discussion}

\section{Trees Outside Forest Statistics}

In the nine compartments made for image analysis, the
Trees Outside Forest count was found to be a total of 31520 with an average of 2700 trees per hectare (Table 2).

\begin{tabular}{|c|c|c|c|}
\hline Compartment & TOF Count & Avg. no. of trees/plot & No. of trees/ha \\
\hline 1 & 465 & 16 & 310 \\
\hline 2 & 711 & 40 & 190 \\
\hline 3 & 420 & 53 & 1750 \\
\hline 4 & 5425 & 88 & 3070 \\
\hline 5 & 10745 & 154 & 4000 \\
\hline 6 & 4600 & 200 & 4610 \\
\hline 8 & 8759 & 231 & 5120 \\
\hline 9 & 3328 & 256 & 5320 \\
\hline Total & 1862 & 266 & 2700 \\
\hline
\end{tabular}

Table 2: Number of trees outside the forest area.

\section{Biomass and Carbon Calculation}

Tree outside forest is also contributing to the national carbon storage accounting. Above Ground Biomass was calculated in terms of tons per hectare for sample plots (See
Supporting Information) and compartments separately. The data shows that the ranges of the biomass in different compartments are 54.8 tons/ha to 149.8 tons/ha with an average of 118.4 tons/ha biomass and 55.6 tons/ha carbon (Table 3) (Figure 5).

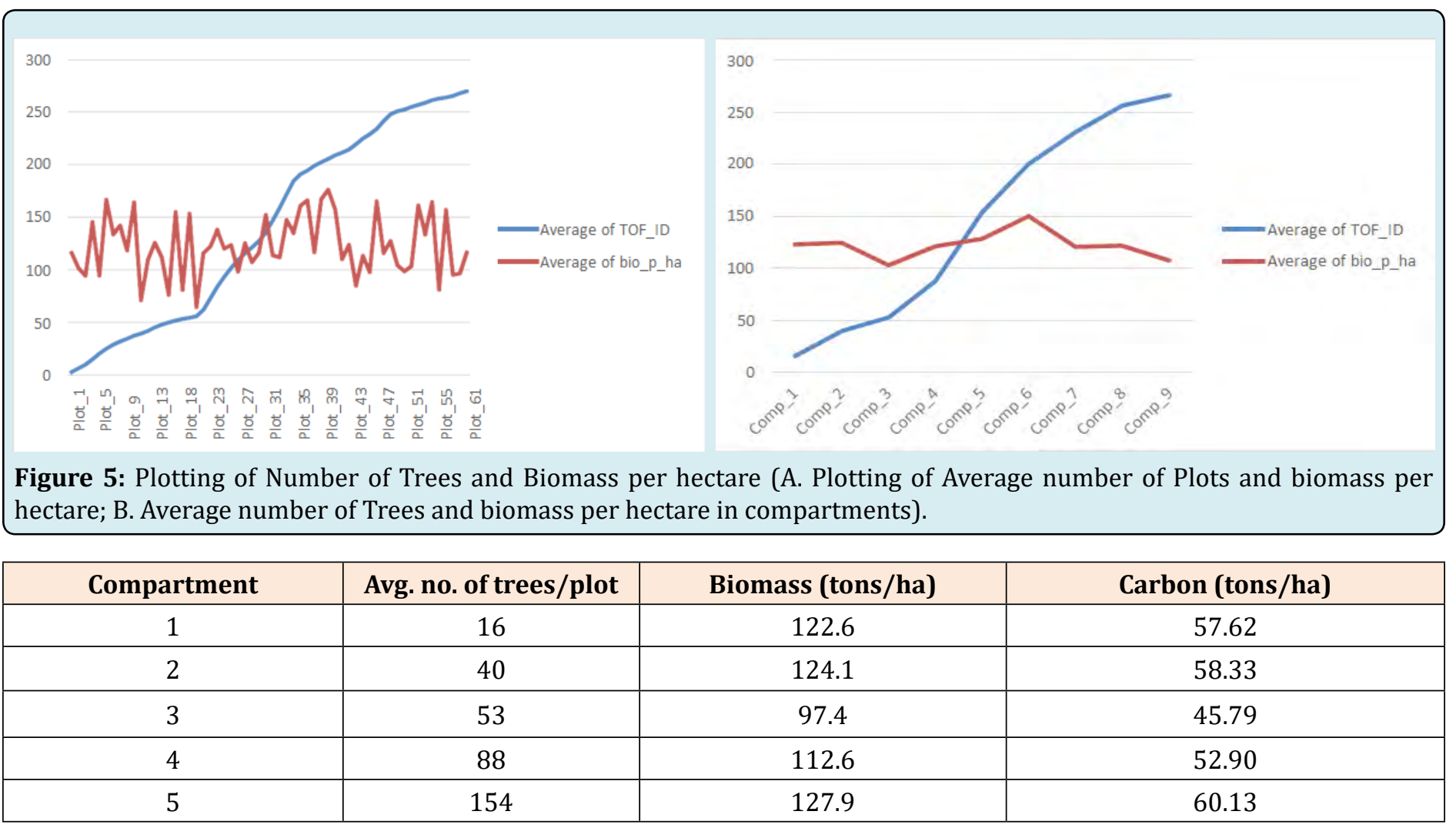


Journal of Ecology and Natural Resources

\begin{tabular}{|c|c|c|c|}
\hline 6 & 200 & 149.8 & 70.42 \\
\hline 7 & 231 & 105.4 & 49.53 \\
\hline 8 & 256 & 106.0 & 49.80 \\
\hline 9 & 266 & 54.8 & 25.74 \\
\hline Total & & 118.4 & 55.6 \\
\hline
\end{tabular}

Table 3: Biomass and Carbon calculation.

\section{Relation between CPA and Biomass}

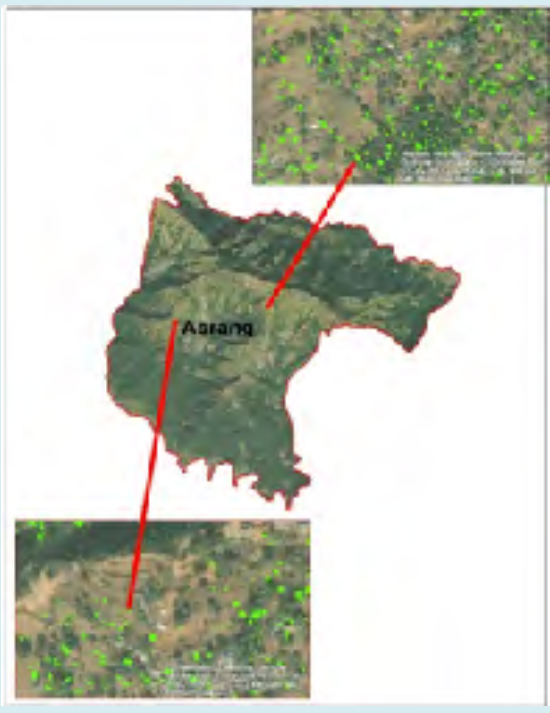

Figure 6: CPA mapped using WorldView PAN data and OBIA.
The CPA of the individual trees was calculated and carried linear best fit analysis with biomass of the trees. The regression best fit showed that the correlation $\mathrm{R}^{2}$ value of 0.7678 (Figure 6).

A study carried out by Kharal, et al. [26] found that the trees outside forest contain $3.3 \mathrm{~m}^{3} / \mathrm{ha}$ stem volumes in Nawalparasi district of Nepal which is quite similar to this research. The total above ground air dried biomass and total above ground oven dried biomass of trees in Middle Mountain forests in Nepal is 143.26 ton/ha and 130.24 ton/ha respectively [27]. Though there is difference in methodology for calculation the biomass storage, the biomass is higher than our study. This shows that the contribution of TOF on carbon sink is potential areas to cover in the carbon quantification. The Government of Nepal also conducts an assessment of Other Wooded Land (OWL) [27] and given the high contribution of TOF in the biomass storage it is high time the Government also include TOF assessment in the national statistics. Such assessment would also be highly beneficial for carbon trading schemes (Figure 7).

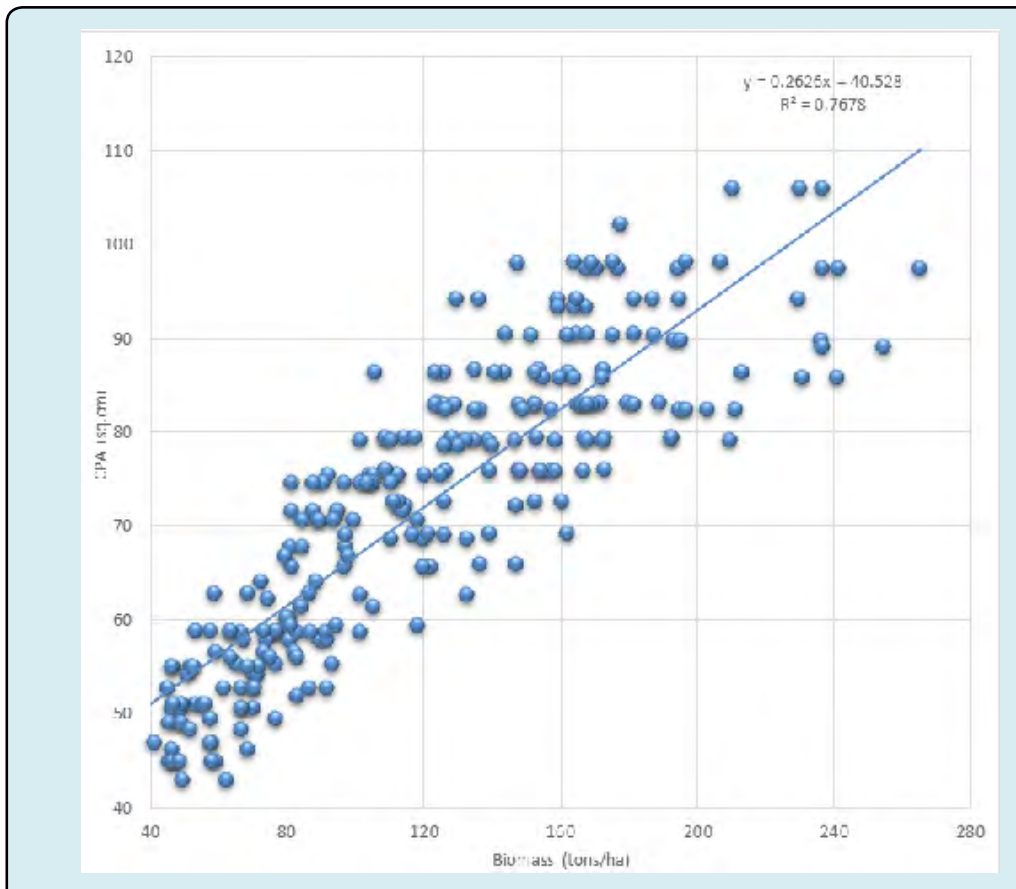

Figure 7: Allometric relation between CPA and biomass of the trees 


\section{Journal of Ecology and Natural Resources}

\section{Conclusion and Recommendations}

From our research, we conclude that the tree outside forest provide important contribution in terms of storage of biomass carbon in Nepal. Hence, we recommend that the contribution from the Trees outside Forest be accounted into the national carbon statistics. Likewise, the methodology of the assessment needs further developments considering multiple sources and field scenarios. There is tremendous contribution on the climate change mitigation from Trees outside forest through carbon storage in the above ground biomass pool. The carbon quantification of the forest trees to show the scope of the above ground biomass in forest trees also need to include the TOF domain which ultimately shows the importance of the farm tress and similar attempts in agroforestry practices. The farm forestry and agroforestry system which tempts the trees outside forest has dual contribution through climate change mitigation and providing livelihood support to the small holding farmers.

\section{Acknowledgement}

Authors extend their gratitude to the data providers namely ICIMOD, ERDAS Innovative Challenge. We would also like to acknowledge support from the locals during the field measurement and survey. We also want to acknowledge Ms. Divya Bhattarai and Dr. Bharat M. Shrestha for their constructive feedback during the conceptualizing the study and preparation of the paper.

\section{Conflicts of Interest}

We declare that authors have no conflicting interest on the publication.

\section{References}

1. Forest Survey of India (2019) India State of Forest Report. Dehradun, India.

2. Zomer RJ, Neufeldt $\mathrm{H}, \mathrm{Xu}$ J, Ahrends A, Bossio D, et al. (2016) Global Tree Cover and Biomass Carbon on Agricultural Land: The contribution of agroforestry to global and national carbon budgets. Scientific Reports 6: 29987.

3. Bellefontaine R, Petit S, Pain 0, Deleporte P, Bertault JG (2002) Trees outside forests: towards better awareness.

4. Idol T, Haggar J, Cox L (2011) Ecosystem services from smallholder forestry and agroforestry in the tropics. Integrating agriculture, conservation and ecotourism: examples from the field. Springer pp: 209-270.

5. Herzog F (2000) The importance of perennial trees for the balance of northern European agricultural landscapes. Unasylva 200: 42-48.

6. FAO/FRA (2000) Global Forest Resources Assessments Food and Agriculture Organization of the United Nations.

7. Pulido FJ, Díaz M, Hidalgo de Trucios SJ (2001) Size structure and regeneration of Spanish holm oak Quercus ilex forests and dehesas: effects of agroforestry use on their long-term sustainability. Forest Ecology and Management 146(3): 1-13.

8. Foresta Hde, Somarriba E, Temu A, Boulanger D, Feuily $\mathrm{H}$, et al. (2013) Towards the assessment of trees outside forests, Rome, Italy.

9. Plieninger T, Hartel T, Martín-López B, Beaufoy G, Bergmeier E, et al. (2015) Wood-pastures of Europe: Geographic coverage, social-ecological values, conservation management, and policy implications. Biological Conservation 190: 70-79.

10. Solomon S (2007) IPCC: Climate change the physical science basis. In Proceedings of the AGU Fall Meeting Abstracts.

11. Gibbs HK, Brown S, Niles JO, Foley JA (2007) Monitoring and estimating tropical forest carbon stocks: making REDD a reality. Environmental Research Letters 2(4): 045023.

12. Beckschäfer P, Schnell S, Kleinn C (2017) Monitoring and Assessment of Trees Outside Forests (TOF), In: Dagar JC, Tewari VP, et al. (Eds.), Agroforestry, Springer Singapore: Singapore pp: 137-161.

13. Schnell S, Kleinn C, Ståhl G (2015) Monitoring trees outside forests: a review. Environmental Monitoring and Assessment 187.

14. Schnell S, Altrell D, Ståhl G, Kleinn C (2015) The contribution of trees outside forests to national tree biomass and carbon stocks-a comparative study across three continents. Environmental Monitoring and Assessment 187(1): 4197.

15. Food and Agriculture Organization (2002) Trees outside forests, a key factor in integrated urban and rural management.

16. Sander H, Polasky S, Haight RG (2010) The value of urban tree cover: A hedonic property price model in Ramsey and Dakota Counties, Minnesota, USA. Ecological Economics 69(8): 1646-1656.

17. Bremer LL, Farley KA (2010) Does plantation forestry restore biodiversity or create green deserts? A synthesis of the effects of land-use transitions on plant species 
Journal of Ecology and Natural Resources

richness. Biodiversity and Conservation 19: 3893-3915.

18. Lumsden LF, Bennett AF (2005) Scattered trees in rural landscapes: foraging habitat for insectivorous bats in south-eastern Australia. Biological Conservation 122(2): 205-222.

19. Plieninger T, Pulido FJ, Schaich H (2004) Effects of landuse and landscape structure on holm oak recruitment and regeneration at farm level in Quercus ilex L. dehesas. Journal of Arid Environments 57(3): 345-364.

20. Chave JC, Andalo S, Brown MA, Cairns JQ Chambers D, et al. (2005) Tree allometry and improved estimation of carbon stocks and balance in tropical forests. Ecosystem Ecology Oceologia 145(1): 87-99.

21. Yadav Y, Chhetri BK, Rayamajhi S, Raj Tiwari K, Kumar BP (2017) Sitaula Importance Of Trees Outside Forest (TOF) In Nepal: A Review.

22. Guo ZD, Hu HF, Pan YD, Birdsey RA, Fang JY (2014) Increasing biomass carbon stocks in trees outside forests in China over the last three decades. Biogeosciences 11: 4115-4122.

23. CBS (2012) National Population Census 2011 Household and Population by Sex Ward Level; Central Bureau of Statistics: Thapathali, Kathmandu.

24. Uddin K, Shrestha HL, Murthy MSR, Bajracharya B, Shrestha B, et al. (2015) Development of 2010 national land cover database for the Nepal. Journal of Environmental Management 148: 82-90.

25. Woodcock CE, Strahler AH (1987) The factor of scale in remote sensing. Remote sensing of Environment 21(3): 311-332.

26. Kharal DK, Giri RK, Karna DL (2008) Assessment of Trees Outside Forest: Nawalparasi District. Department of Forest Research and Survey, Kathamndu, Nepal.

27. DFRS (2015) State of Nepal's forests, Department of Forest Research and Survey: Kathmandu. Nepal: 9789937-8896-3-6. 